\title{
College Physics Teaching Reform under the Background of Innovation and Entrepreneurship
}

\author{
Xiang Teng ${ }^{1, a}$, Yanhui Zhang ${ }^{2, b}$ \\ ${ }^{1}$ Basic Teaching and Research Institute, Bohai University, Jinzhou, 121013, China \\ ${ }^{2}$ School of Mathematics and Physics, Bohai University, Jinzhou, 121013, China \\ ayq8369@163.com, ${ }^{\mathrm{b}}$ Cinderella0o0@163.com
}

Keywords: innovation and entrepreneurship; college physics; teaching reform; teaching system; ability training; implementation route

\begin{abstract}
It is a major strategic measure to serve for an innovative country's construction that colleges carry out the innovation and entrepreneurship education, and cultivate college students' abilities of innovation and entrepreneurship. College physics is an important compulsory foundation course of colleges' science and engineering specialties which plays an important role in cultivating and developing students' creative thinking, innovation consciousness and practice ability. This project's researches build the comprehensive information teaching system, put forward to strengthen college students' innovative practice ability training course, plan college physics teaching reform's implementation route, which is in view of the problems existing in the traditional college physics teaching. This project's research results guide for the theoretical guidance of the college physics teaching reform, provide the impetus for the cultivation of the college students' innovation and entrepreneurship and applicable talents training, provide the reference for colleges' science and engineering practical foundation course teaching reform.
\end{abstract}

\section{Introduction}

Innovative country needs innovative talents, the key of innovative talents training lies in the innovative teachers and innovative measures. At present, our country has already entered the public entrepreneurship, a new era of mass innovation. In the face of national new development needs, colleges must keep pace with the times, strongly promote colleges' teaching reform, characteristic development and quality improvement. Therefore, it is imperative to deepen colleges' teaching reform. College physics is an important compulsory basic course of the college's science and engineering specialty, which plays an irreplaceable role in cultivating and developing students' innovative thinking, the innovative consciousness and innovative practice ability. Through college physics learning, students can not only obtain basic abilities of the scientific thinking, scientific analysis and scientific calculation, also can cultivate the scientific development spirit and the original motivation, which provides the source and impetus for further innovation and entrepreneurship. The talents training mode reform of the college physics teaching reform which is under the background of innovation and entrepreneurship talents has an important demonstration and guidance role. How to provide the impetus for the cultivation of students' innovation and entrepreneurship, and applicable talents training, also promote and apply practical experience and results through the classroom teaching of college physics courses and the reform of the experimental teaching, which is the focus of colleges' teaching reform.

\section{Existing Problems in Traditional College Physics Teaching}

For a long time, there exists obviously attention on theory rather than practice in the domestic colleges' college physics teaching; attach great importance to imparting knowledge, despise the innovation practice ability; pay attention to teachers' "speak", and neglect students' "learning"; pay attention to summative evaluation, despise the disadvantages such as process evaluation, which seriously influences to students' innovative practice ability training and comprehensive quality 
improvement, as well as restricting students' potential and long-term development. Existent problems include the following four aspects:

First, teaching content is lack of pertinence and hierarchy. The formative course teaching system is lack of pertinence and hierarchy in a long time, which is difficult to meet the needs of students at different levels and different majors. The college physics teaching material is universal, and the college physics teaching rarely integrates into the content of innovation and entrepreneurship.

Second, Theory and practice courses setting are not reasonable. College physics attaches importance to the theory, despise the experiment, experimental classes are an adjunct to theory classes, experimental classes, experimental hours are less, experimental results account for a small proportion of total scores, students do not attach importance to the experiment. For a long period of time, the teaching model which takes the theory as the main point and despises the practice has seriously influenced the improvement of students' learning interest.

Third, teaching methods, means and evaluation are out dated. Teachers' classroom teaching methods are traditional and single, which lacks the cultivation on students' innovative thinking; teaching methods are appropriate, or a traditional chalk blackboard writing, or a single multimedia teaching; evaluation ways are simple and rigid, which pays attention to the summative assessment and despises process assessment, experiment report scores accounts for a large proportion, it is not conducive to encouraging the cultivation of students' innovation and practice ability.

Forth, experimental teaching contents are old curing thinking. Experimental teaching contents are obsolete, more validation experiments, experimental technology is relatively backward; experimental selected topics are conditioned by instruments and equipments; experiments are done under the guidance of teachers, students have no thinking space, which is not conducive to students' innovative thinking, innovative consciousness and innovative practice ability training.

\section{Construction on Omnibearing Informationization Teaching System}

The traditional information teaching system takes network as the technology platform, construction thought of network teaching resources is old, which can not very well reflect the superiority of the network education, too much emphasis on the "content" or "education", or the simple display of teaching resources, neglect the track and support for learning process and specific teaching links, there are obvious defects or deficiencies in the actual application process. Information is the process of a new technology diffusion, which takes information resources development and utilization as the core, based on the high technology such as the network technology and communication technology. The information teaching system refers to that roundly and deeply applying modern information technology into the field of education, which promotes the architecture of the education reform and development. Characterized by digital, networked, intelligent and multimedia, which is an open, sharing, communication and collaboration system. Taking education information resources as basic composed elements of the education system, and applying the information technology into various areas of the education widely, in accordance with the requirements of innovative talents training, adopting the information technology explores a new education mode, so as to promote the education modernization.

The college physics courses teaching reform is oriented to students, which takes innovation ability training as the core, serving the employment as the ultimate goal, in the overall design of the teaching system, it emphasizes the cultivation of innovation practice ability in the process of learning, integrating innovation and entrepreneurship thinking, and practical innovation ability development services that all teaching activities for students to achieve the goal of improving students' employment ability. The hierarchical and gradual omnibearing information teaching system built by the project pays attention to the innovation teaching method design and establishment of appropriate teaching circumstances, constructs six principles which follow teaching, control, simplicity, scientific, practical and artistic. The teaching idea which takes students as the main body and teachers as the leading factor, improving students' innovation thinking ability, comprehensive application ability and practical ability as the teaching goal. The omnibearing information teaching system model is shown in Fig. 1. 
The information teaching system implementation needs the support of teaching resources. Information redesign to cope with existing teaching resources makes the deduction of teaching contents more intuitive, clear and easy to understand, gives full play to the role of modern education technology, and follows the teaching law and students' cognitive regularity, which presents the best teaching environment for students. In the process of teaching resources redesign, teachers adopts the modern information technology to make teaching and demonstration experiment teaching resources, in the construction of auxiliary teaching resources, self-test questions and electronic materials are developed. Distance tutoring for students can be done through the network; students can use the network to collect the relevant professional knowledge and understand frontier development trends, also find the information and data what they need.

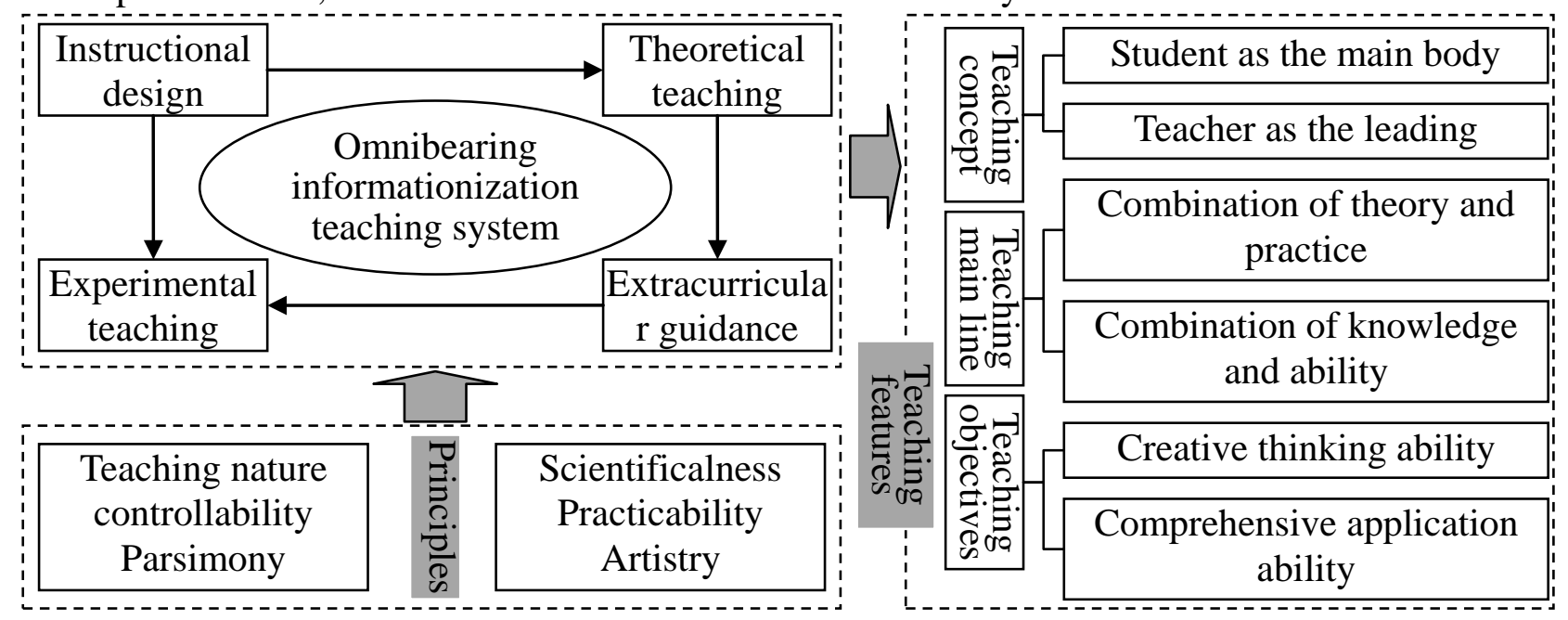

Fig. 1. Informationization teaching system on college physics teaching

\section{Strengthening the Cultivation of College Students' Innovative Practical Ability}

Cultivating students' innovative practice ability is one of core goals of higher education reform. The cultivation of college students' innovative practice ability depends on the students' active participation and teachers' correct guidance, as well as good atmosphere conditions. Therefore, three aspects' constructions are mainly strengthened: first, respect students' principal position, elaborate students' enthusiasm and initiative. Students' principle position should be reflected in all aspects of personnel training, throughout talents training all along, which makes up the option to return to students. Through correctly choosing planning objectives develops innovative quality and capability. Constructing the innovative talents training system provides more choices for students development; strengthening the teaching construction provides a wealth of choice content for students becoming talents. Second, strengthen teachers' sense of responsibility, full play the leading role of teachers. Teachers should convert the traditional education concept which takes knowledge inheritance as the center, and set up the innovative education concept, which puts college students' innovative practice ability training at an important position. Teachers should enhance the sense of responsibility and self-consciousness of educating people. Responsible for teaching work, and responsible for students, as well as concerned about the growth of students. Teachers also should actively improve their knowledge structure, and constantly improve the ability of innovation practice. Third, create a good institutional environment, construct a harmonious education atmosphere. College education environment includes various aspects such as the consciousness concept environment, teaching management environment, academic exchange environment, humanistic atmosphere environment, information network environment, hardware facilities environment, the key is the institutional environment and campus culture atmosphere. Actively reform and adjust the school teaching management, students management and teachers management system to create a good institutional environment for the innovative talents cultivation. Strengthen the campus culture construction, give play to the important role of campus culture on college 
students' becoming talents. The cultivation of students' innovative practice ability training in the college physics teaching should be carried out from two aspects that the experiment teaching and practice teaching, the training process is shown in Fig. 2.

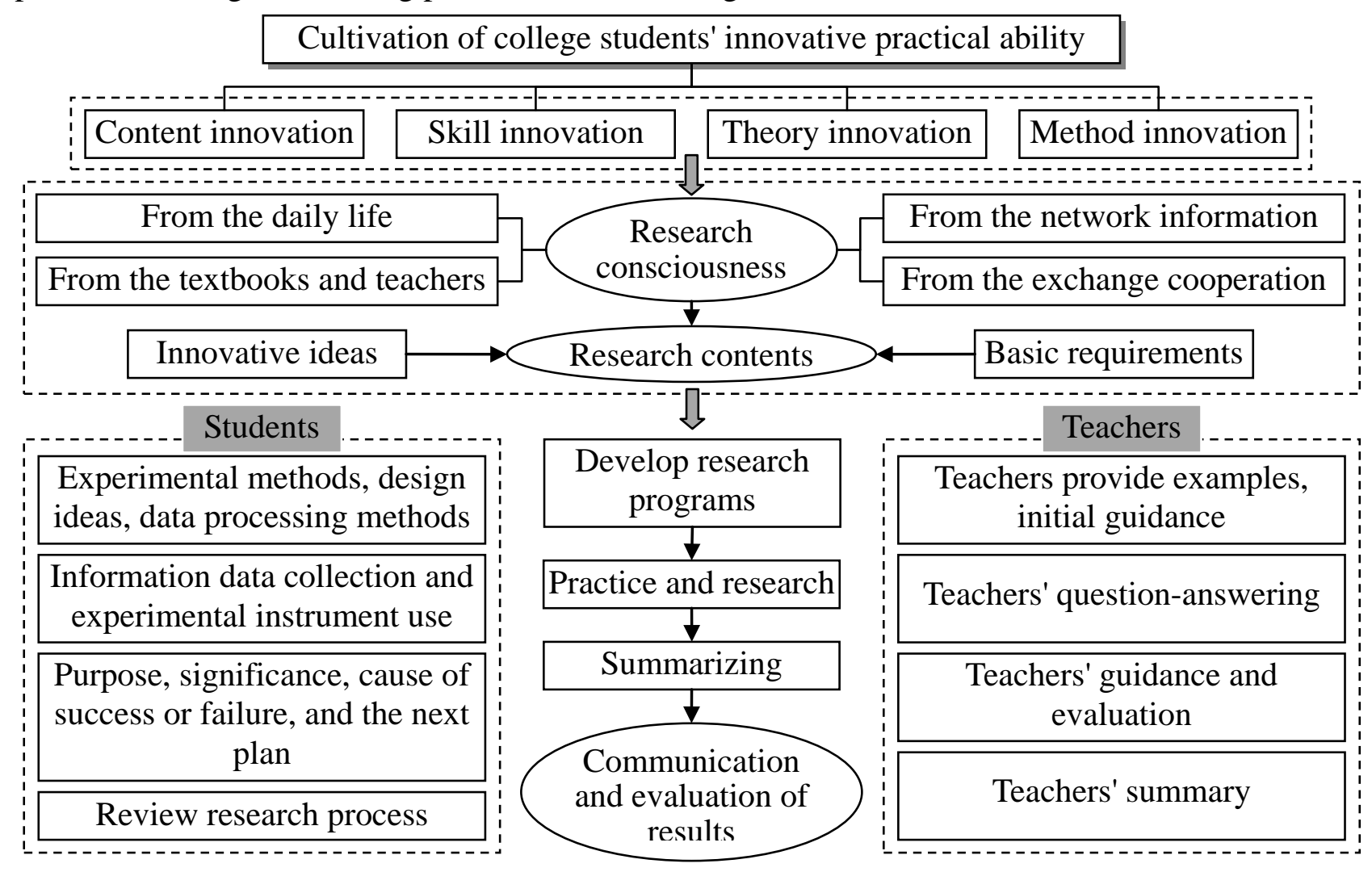

Fig. 2. Cultivate Process of College Students' Innovative Practical Ability

First, attach importance to the experimental teaching, cultivate the innovation ability. Physics is a natural science based on experiments, physical experiments are also an important activity for human to know the world, which plays a huge promoting role for the development of physics, without physical experiments, there is no development of physics. Moreover, there are complement and inseparable relationship between the learning of physics knowledge and physical experiments. Therefore, more attention should be pay to the experimental teaching in the process of physics teaching to cultivate students' scientific attitude in seeking the truth from facts, and cultivate students' ability to analyze and solve practical problems, and cultivate students' innovative spirit. Schools should actively create conditions and fully open laboratories to provide students with plenty of experimental room. Allow students to conduct independent experiments to make full use of laboratory resources to carry out extra-curricular activities.

Second, establish the practice base, multi-channel training the innovation practice ability. College physics teaching is a course closely integrated with social production practice, which guides students to participate in the enterprise practice and participate in enterprise scientific projects, and extends the theory classroom teaching to provide the comprehensive real teaching practice platform for students, cultivate students' innovative thinking, innovative consciousness and innovative practice ability. Colleges' competent departments should strengthen the construction of school innovation practice community base, support and encourage students to participate in all kinds of competition activities dominated by teachers, which takes students as the main body, which provide a strong support for students' innovative spirit, innovative thinking and innovative consciousness, as well as the training of innovative practice ability. At the same time, we should focus on guiding students to know themselves and develop themselves. Students through a variety of opportunities and platforms anneal that they are not fear of failure, their life attitude of the pursuit of excellence, as well as the enterprising and persevering spirit quality. 


\section{Implementation route on College Physics Teaching Reform}

The project is characterized by highlighting the innovation thinking, innovation consciousness and the cultivation of innovative practice ability, which takes the teaching, effectiveness and scientific, practicability, rigor and practical orientation as the basic principle, adhering to the teaching concept that students as the main body, teachers as the leading, set up the autonomous learning in the students extracurricular, the teaching link of college physics consist of teachers' incisive explain, concise, interaction, testing and other elements in the classroom, in order to improve students' innovation and entrepreneurship awareness to achieve the basic goal of building a efficient ecological classroom and cultivating applicable talents. Protruding the affect of information technology as an effective teaching method in the process of classroom teaching, show teachers' teaching personality and characteristics, reform traditional teaching methods, effectively and reasonably adopting modern teaching means reflects the teaching process, pay attention to the advantages that deductive process and clear steps of teaching contents are easy to understand, follow the rules of education teaching and students' cognitive regularity which makes the teaching process optimization. The college physics teaching reforms with the integration of imparting knowledge, cultivating the ability and improving the quality from the construction of full range of the information innovation teaching system, the application of various forms of flexible innovation teaching methods, the redesign of traditional teaching resources information, students' whole process multi dimensional assessment and evaluation, as well as the science of history of physics fit into the teaching system and other aspects. The route of reform implementation is shown in Fig. 3.

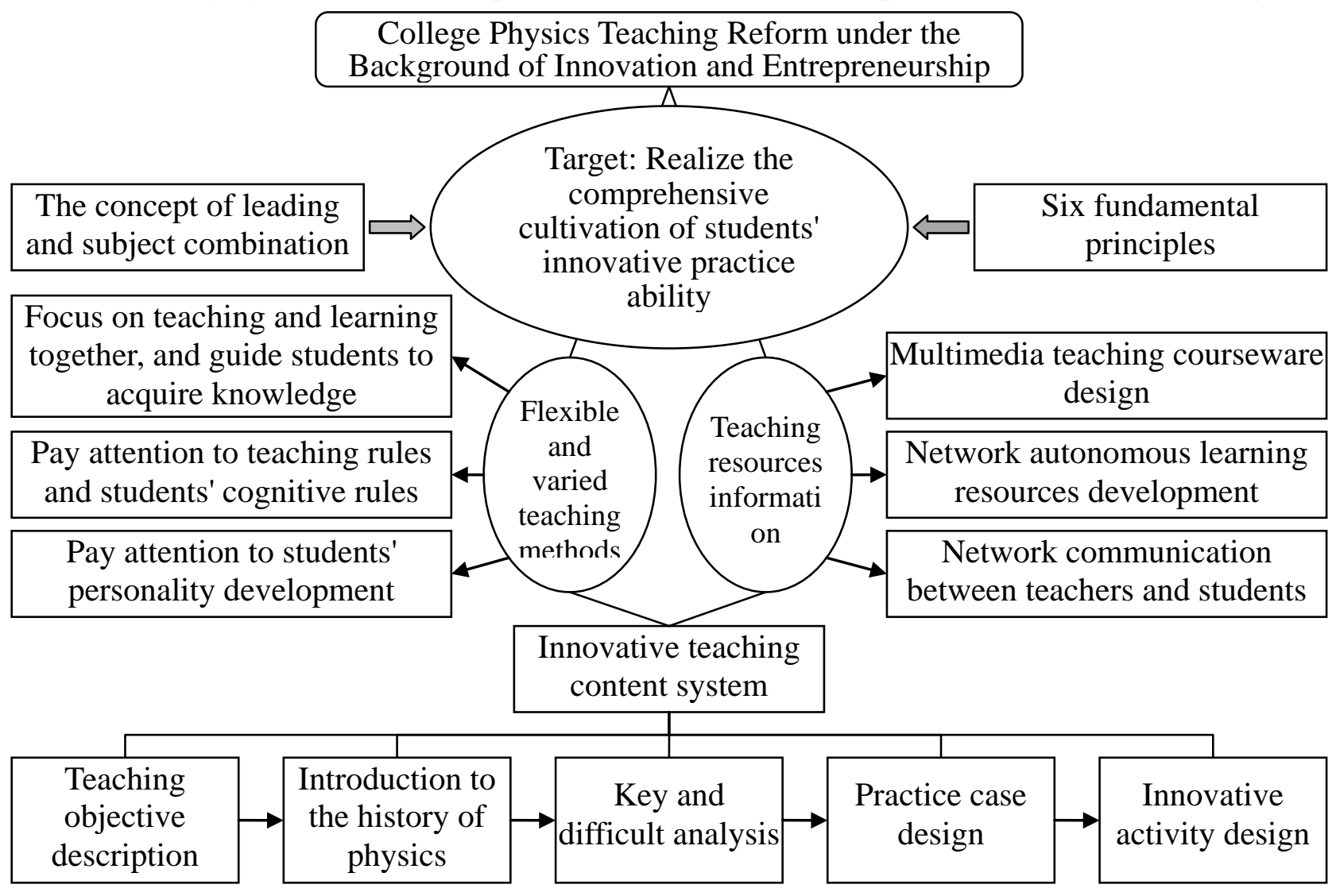

Fig. 3. Implementation route on college physics teaching reform

under the background of innovation and entrepreneurship

\section{Conclusion}

College teaching reform is a complicated system project, the teaching reform implementation is completed which needs to rely on colleges' teachers and students. The reform of college physics theory teaching and experiment teaching under the background of innovation and entrepreneurship, 
highlighting the cultivation of students' innovative ability and practical ability, the introduction of innovative and entrepreneurship education is a beneficial attempt to cultivate applicable talents. In the national "public entrepreneurship, people innovation" environment, how to consolidate, enrich and test the theoretical knowledge and practical skills which are taught in the classroom, and make students develop themselves, effectively transform knowledge into students' ability, wisdom, spirit and character, construct a suitable college physics teaching mode, comprehensively improve the level of theory and experiment teaching, research results can provide references for college physics teaching and colleges' science and engineering practical foundation course teaching reform.

\section{Acknowledgement}

This work is supported by 2015 annual teaching reform project in Bohai university (BDJG-15-YB-A-002): Exploration and Research on Intensive Lecture Link for Rotation Classroom; 2016 annual undergraduate teaching reform research project of general higher education in Liaoning: Research on college physics teaching reform under the background of innovation and entrepreneurship.

\section{References}

[1] F. Q. Zhang, X. L. Lin, X. Wang, "Research on the teaching reform of college physics experiment under the cultivation of creative talents," College Physics, vol. 36, no. 3, pp. 36-39, 2017.

[2] H. R. Li, X. L. Wang, P. B. Tian, "The reform of college physics teaching based on the cultivation of innovative talents," China University Teaching, vol. 35, no. 8, pp. 19-21, 2013.

[3] Baidu Wenku, "Attach importance to experimental teaching, cultivate innovation ability," https://wenku.baidu.com/view/74938c0aaaea998fcc220e72.html, 2017-4-10.

[4] Z. Y. Zhang, H. Zhou, "Construction of service oriented information teaching system," Modern Computer, vol. 27, no. 9, pp. 12-15, 2011.

[5] L. M. Zhang, N. Song, "Exploration and Practice of College Physics Teaching Reform in Independent Colleges," Education Teaching Forum, vol. 9, no. 10, pp. 137-138, 2017.

[6] B. Q. Liu, "On the reform of college physics teaching based on the cultivation of applied technical talents," Journal of Huanggang Normal University, vol. 36, no. 6, pp. 84-87, 2016. 